\title{
Impact of a Specialized Ambulatory Clinic on Refractory Breathlessness in Subjects With Advanced COPD
}

\author{
Amany F Elbehairy, Hannah McIsaac, Elizabeth Hill, Patrick A Norman, Andrew G Day, \\ J Alberto Neder, Denis E O'Donnell, and Ingrid A Harle
}

\begin{abstract}
BACKGROUND: Severe exertional dyspnea is a commonly reported symptom in patients with COPD, especially in the advanced stages. Our objective was to assess the preliminary impact of comprehensive, individualized management provided by a specialized tertiary center clinic on exertional dyspnea and patient-centered outcomes in patients with advanced COPD. METHODS: This retrospective analysis included 45 subjects with COPD who were evaluated in a newly established dyspnea clinic over 3 years. Those with severe exertional dyspnea (Medical Research Council dyspnea score of $\geq 4 / 5$ ), despite optimal disease-targeted therapy were eligible for referral. We used the revised Edmonton Symptom Assessment System (ESAS-r) to assess symptoms. Responders were defined as those whose change from baseline to 2-months met the minimum clinically important difference of $\leq-1$ in ESAS-r score for shortness of breath. RESULTS: Subjects (mean \pm SD age $70 \pm 7$ years) had an average $F_{1}$ of $36 \pm 18 \%$ predicted and a Medical Research Council dyspnea score of $4.7 \pm 0.4$. Responses to the intervention were variable and mean change in the ESAS-r score for shortness of breath in the total group was $-\mathbf{0 . 3 2} \pm \mathbf{3 . 3 9}, P=\mathbf{. 5 3}$. Forty-seven percent of the subjects were identified as responders, and $42,40,40$, and $33 \%$ met the minimum clinically important difference for improvement in ESAS-r scores for tiredness, anxiety, well-being, and depression, respectively. Responders had fewer emergency department annual visits in the 2 years after their first clinic visit compared with nonresponders (mean $\pm \mathrm{SD}, 1.38 \pm 1.63$ vs $4.45 \pm 5.52, P=.034$ ). CONCLUSIONS: Although the impact of our specialized advanced dyspnea clinic was variable, as evaluated by the ESAS-r, it provided measurable additional clinically important benefit to almost half of the subjects with advanced COPD and severe refractory dyspnea. Key words: dyspnea; COPD; comprehensive management; palliative care. [Respir Care 2020;65(4):444-454.

(C) 2020 Daedalus Enterprises]
\end{abstract}

\section{Introduction}

Breathlessness (dyspnea) is the most commonly reported symptom in patients with COPD, a devastating disease predicted to be the third leading cause of death worldwide by $2020 .^{1,2}$ The severity of dyspnea increases with age and

\footnotetext{
Dr Elbehairy, Ms McIsaac, Ms Hill, Dr Neder, Dr O’Donnell, and Dr Harle are affiliated with Palliative Care and Respirology Divisions, Department of Medicine, Queen's University and Kingston Health Sciences Centre, Kingston, Ontario, Canada. Dr Elbehairy is affiliated with the Department of Chest Diseases, Faculty of Medicine, Alexandria University, Alexandria, Egypt. Mr Norman and Mr Day are affiliated with the Kingston General Health Research Institute, Kingston Health Sciences Centre, Kingston, Ontario, Canada.
}

disease progression, ${ }^{3}$ and is a more accurate predictor of mortality among patients with COPD than is impairment of lung function. ${ }^{4}$ In fact, as many as $95 \%$ of patients with advanced COPD experience breathlessness during mini-

\footnotetext{
The authors have disclosed no conflicts of interest. This study was sponsored by a research grant from Boehringer Ingelheim (Investigator Initiated Trial \# 1237-0079).

Correspondence: Denis O’Donnell PhD FRCPI FRCPC, Respirology Division, Department of Medicine, Queen's University and Kingston Health Sciences Centre, 102 Stuart Street, Kingston, Ontario, Canada K7L 2V6. E-mail: odonnell@queensu.ca.
}

DOI: $10.4187 /$ respcare.06950 
mum exertion. ${ }^{5}$ In addition, such patients exhibit many other comorbid conditions that contribute to respiratory discomfort and decreased cardiorespiratory fitness related to a sedentary lifestyle. ${ }^{2}$

Evidence-based pharmacologic and nonpharmacologic treatment options for breathlessness in patients with chronic respiratory diseases are sparse and are generally underused. ${ }^{6-8}$ Apart from the use of bronchodilators and inhaled corticosteroids, as the first step in dyspnea management in patients with COPD, a variety of drugs have been proposed for treatment of breathlessness (eg, opioids, benzodiazepines, methotrimeprazine, cannabinoids), ${ }^{6,9}$ but there is little concrete evidence to support their routine use. In this context, a trial of opiates has been recommended as a treatment for refractory dyspnea in selected patients with COPD. ${ }^{6}$

Despite our increased understanding of the complex neurobiology of dyspnea, effective dyspnea relief for many individuals remains an elusive goal. To address the growing need to improve quality of life in patients with advanced COPD who remain breathless despite optimal disease-targeted pharmacotherapy, we established a new advanced dyspnea clinic at our center under the leadership of a palliative care specialist, nurse practitioner, and respirologists, with a particular interest in refractory dyspnea management. Only patients with chronic severe exertional dyspnea, defined by a score of $\geq 4$ of 5 on the Medical Research Council (MRC) dyspnea scale, ${ }^{10}$ referred exclusively by a respiratory specialist, were eligible for assessment and treatment in this clinic. To our knowledge, this was the first clinic of its kind in Canada; the purpose of the current article was to describe the components of the program, to share our experience to date, and to examine its impact on patient-centered outcomes throughout the duration of treatment.

The overall rationale for effective management of dyspnea was, first, to optimize respiratory mechanics (bronchodilator combinations) as much as possible; second, in carefully selected patients, to reduce the increased respiratory neural drive to breathe (eg, supplemental oxygen, opiates), without clinically compromising alveolar ventilation; and third, to assist in improving quality of life as much as possible. These combined therapies would ensure that neuromechanical coordination of the respiratory system was partially restored to achieve an associated subjective benefit. ${ }^{69}$ Also, every attempt was made to address the often dominant affective and psychosocial components of severe dyspnea, and to offer individualized end-of-life counseling. We postulated that an integrated approach based on this rationale (see above) would provide important palliative care support for such patients and result in significant improvements in validated outcomes, such as symptom severity scores when using the revised version of the Edmonton Symptom Assessment System (ESAS-r). ${ }^{11}$ We,

\section{QUICK LOOK}

\section{Current knowledge}

Severe exertional dyspnea is a commonly reported symptom in patients with COPD, especially in advanced stages. Evidence-based pharmacologic and nonpharmacologic interventions for dyspnea relief are available but generally underused. The role of comprehensive management and palliative care is well documented in symptomatic patients with thoracic cancer, but data about the role of similar service in improving symptoms and patient-centered outcomes in those with noncancerous chronic respiratory diseases are sparse.

\section{What this paper contributes to our knowledge?}

The study provided insights into the role of a specialized advanced dyspnea clinic in improving dyspnea and other patient-centered outcomes in subjects with advanced COPD. The comprehensive service provided ensured a well-structured discussion about endof-life care and provided measurable clinically important benefits to some subjects who were symptomatic. The positive preliminary results cannot be generalized but do set the stage for new randomized studies to evaluate the role of specialized clinics for palliative care in patients with chronic respiratory diseases and refractory dyspnea despite disease-specific therapy.

therefore, undertook a retrospective pre-post analysis to examine the impact of comprehensive integrated management provided by this specialized clinic on symptoms (ESAS-r as a primary outcome) and other important patient-centered outcomes (hospital admission and emergency visits as a secondary outcome).

\section{Methods}

\section{Subjects and Study Design}

This was a retrospective study that included patients with advanced COPD who had attended the advanced dyspnea clinic at Hotel Dieu Hospital and Kingston Health Sciences Centre (Kingston, Ontario, Canada) between 2013 and $2016(N=62)$. Given that the patients were not followed up at fixed and/or similar intervals, we identified 45 subjects of the 62 patients who had a follow-up visit between 1 and 3 months after the initial (baseline) visit and labeled this the 2-month follow-up visit to assess for symptomatic responses. 


\section{Integrative Management of Severe Breathlessness in COPD}

Table 1. Overall Pharmacologic and Nonpharmacologic Interventions Provided Through the Clinic

\begin{tabular}{ll}
\hline \hline \multicolumn{1}{c}{ Pharmacologic } & \multicolumn{1}{c}{ Nonpharmacologic } \\
\hline $\begin{array}{l}\text { Optimization of disease-specific } \\
\text { therapy }\end{array}$ & $\begin{array}{c}\text { Referral for pulmonary } \\
\text { rehabilitation }\end{array}$ \\
$\begin{array}{c}\text { Short- and long-acting opiates with } \\
\text { close monitoring of } \mathrm{CO}_{2} \text { levels }\end{array}$ & $\begin{array}{c}\text { Referral for community } \\
\text { palliative care service } \\
\text { Methotrimeprazine }\end{array}$ \\
Management of exacerbations & Sleep hygiene \\
End-of-life discussion \\
comomorbidities & Psychosocial support and panic \\
Oxygen therapy & control \\
& Noninvasive ventilation \\
& Walkers and home equipment to \\
& assist with mobility and \\
& safety \\
\hline
\end{tabular}

The Queen's University and Affiliated Teaching Hospitals Research Ethics Board approved the analysis of these anonymous data sets (DMED-2187-18). Inclusion criteria were patients with a primary diagnosis of severe to very severe COPD and severe breathlessness (ie, an MRC dyspnea score of $\geq 4$ of 5), despite optimum disease-specific pharmacotherapy and with at least one follow-up visit at this specialized clinic. Patients referred by respirologists and who met the inclusion criteria were evaluated by an experienced nurse practitioner $(\mathrm{EH})$ and a palliative care physician specialist (IAH). The main components of individualized management of subjects who attended this specialized clinic are outlined in Table 1 and Figure 1.

\section{Data Collection}

Data were collected from subjects' electronic and paper charts. All data were entered into one database for a multifactorial evaluation of subjects' outcome and well-being. Data included subjects' baseline characteristics (demographics and lung function tests), symptom questionnaires at baseline and over the treatment period, and interventions (pharmacologic and nonpharmacologic) that were first introduced through this clinic. In addition, information about the frequency of (and reason for) annual hospital admissions and emergency department (ED) visits 1 year before and 2 years after the first clinic visit were collected.

Questionnaires included MRC dyspnea scale, ${ }^{10}$ ESAS-r (as a primary outcome), ${ }^{11}$ and palliative performance scale. ${ }^{12}$ The ESAS-r is a 9-item scale: the 9 items are pain, tiredness, drowsiness, nausea, lack of appetite, shortness of breath, depression, anxiety, and well-being. ${ }^{11}$ The ESAS-r numerically rates each of these items on a $0-10$ scale, 0 being none (absence of symptoms) and 10 being the worst possible severity. ${ }^{11,13,14}$ The minimum clinically important difference cutoff for improvement/deterioration in ESAS-r was found to be $1 /-1$ for individual item scores. ${ }^{13,15}$ The palliative performance scale ranges, in $10 \%$ increments, from $0-100 \%$, in which $0 \%$ indicates death and $100 \%$ indicates full performance. ${ }^{12}$

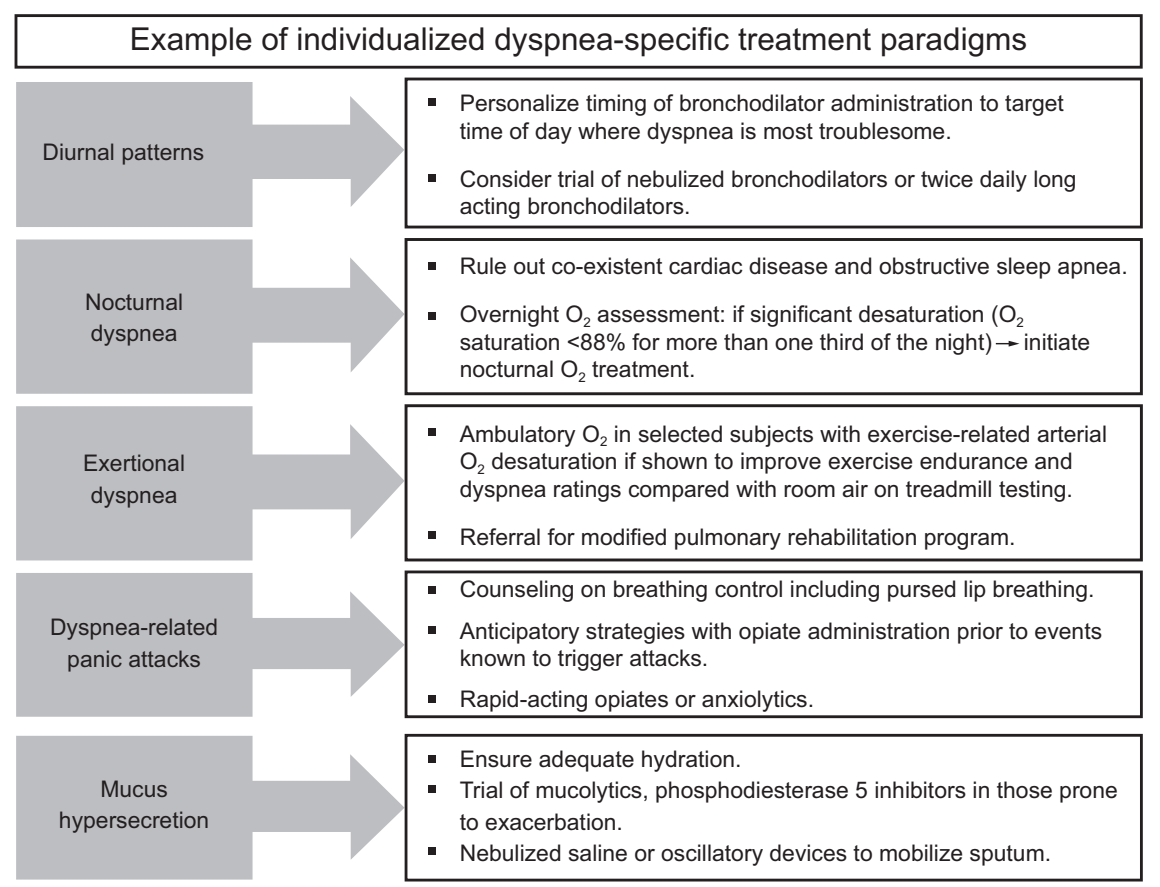

Fig. 1. Example of individualized dyspnea-specific treatment paradigms offered to the subjects during the clinic visit. 


\section{Statistical Analysis}

Data were analyzed by using the Statistical Package for Social Sciences (SPSS ver. 24) and SAS software (SAS ver.9.4TS1M4, SAS/STAT ver.14.3) (SAS Institute, Cary, North Carolina). A change in ESAS-r symptoms score for the shortness of breath domain over the treatment period was the primary outcome measure. Secondary outcome measures included frequency of ED visits and hospital admissions 2 years after the first clinic visit. We also quantified the numbers of program participants availing, for the first time, of structured end-of-life discussions.

The paired $t$ test was used to examine the changes in ESAS-r scores, and the Wilcoxon signed-rank test was used to compare ED visits and hospital admission in the year before and the second year after the first clinic visit. Responders were defined as those who met the minimum clinically important difference $(\leq-1)$ for the ESAS-r score for shortness of breath domain at follow-up. The Fisher exact test was used to compare binary variables, the 2-sample $t$ test was used to compare age, baseline lung function tests and the Wilcoxon rank-sum test was used to compare body mass index, annual ED visits, and hospital admission between responders and nonresponders. We considered $P<.05$ statistically significant, and due to the exploratory nature of this analysis, we did not correct for multiplicity of tests.

\section{Results}

\section{Subject Characteristics and Interventions Through the Clinic}

Sixty-two patients with advanced COPD attended this clinic between 2013 and 2016. As stated in the methods section, the current analysis included only 45 subjects of 62 patients who had a follow-up visit between 1 and 3 months after the initial (baseline) visit. The patients excluded from the pre-post analysis did not have a follow-up visit within the pre-specified time frame, or were lost to follow up, or enrolled in a community palliative outreach clinic. At their first visit, the subjects had severe to very severe airway obstruction $\left(\mathrm{FEV}_{1}\right.$ of $36 \pm 18 \%$ predicted, mean $\pm \mathrm{SD}$ ) and the majority (84\%) were exsmokers. The subjects had evidence of resting hyperinflation (total lung capacity of $135 \pm 34$ and functional residual capacity of $179 \pm 49$, both as percent predicted), pulmonary gas trapping (residual volume per total lung capacity: $62 \pm 12 \%$ ), and moderate reduction in lung diffusing capacity for carbon monoxide ( $50 \pm 14 \%$ predicted). As per referral requirements, the subjects had severe chronic activity-related dyspnea (MRC dyspnea score of $4.7 \pm 0.4$ [mean $\pm \mathrm{SD}])$. Twenty-seven subjects (60\%) were already on oxygen therapy before referral. The general baseline
Table 2. Subjects' Baseline Characteristics

\begin{tabular}{|c|c|}
\hline Characteristic & Results \\
\hline Men/women, $n$ & $25 / 20$ \\
\hline Age, mean $\pm \mathrm{SD} y$ & $70 \pm 7$ \\
\hline Body mass, mean $\pm \mathrm{SD} \mathrm{kg}$ & $68 \pm 21$ \\
\hline Height, mean $\pm \mathrm{SD} \mathrm{cm}$ & $162 \pm 18$ \\
\hline $\mathrm{BMI}$, mean $\pm \mathrm{SD} \mathrm{kg} / \mathrm{m}^{2}$ & $29 \pm 17$ \\
\hline \multicolumn{2}{|l|}{ Smoking status, $n(\%)$} \\
\hline Current & $4(9)$ \\
\hline Ex-smoker & $38(84)$ \\
\hline Not available & $3(7)$ \\
\hline Smoking history, mean \pm SD pack-year & $47 \pm 19$ \\
\hline MRC dyspnea score (1-5), mean $\pm \mathrm{SD}$ & $4.7 \pm 0.4$ \\
\hline Baseline PPS, mean \pm SD $\%$ & $58 \pm 7$ \\
\hline \multicolumn{2}{|l|}{ Pulmonary function test, mean \pm SD } \\
\hline $\mathrm{FEV}_{1}, \%$ predicted & $36 \pm 18$ \\
\hline FVC, $\%$ predicted & $66 \pm 17$ \\
\hline $\mathrm{FEV}_{1} / \mathrm{FVC}, \%$ & $37 \pm 12$ \\
\hline Inspiratory capacity, $\%$ predicted & $74 \pm 24$ \\
\hline TLC, $\%$ predicted & $135 \pm 34$ \\
\hline FRC, $\%$ predicted & $179 \pm 49$ \\
\hline $\mathrm{RV}, \%$ predicted & $224 \pm 77$ \\
\hline $\mathrm{RV} / \mathrm{TLC}, \%$ & $62 \pm 12$ \\
\hline $\mathrm{D}_{\mathrm{LCO}}, \%$ predicted & $50 \pm 14$ \\
\hline $\mathrm{D}_{\mathrm{LCO}} / \mathrm{V}_{\mathrm{A}}, \%$ predicted & $65 \pm 20$ \\
\hline $\mathrm{TLC}-\mathrm{V}_{\mathrm{A}}, \mathrm{L}$ & $3.68 \pm 1.34$ \\
\hline \multicolumn{2}{|l|}{ Inhaled medications, $n(\%)$} \\
\hline SABA & $40(89)$ \\
\hline SAMA & $17(38)$ \\
\hline LABA & $1(44)$ \\
\hline LAMA & $36(80)$ \\
\hline ICS & $4(41)$ \\
\hline ICS/LABA & $40(89)$ \\
\hline $\begin{array}{l}N=45 \\
\text { BMI = body mass index } \\
\text { MRC = Medical Research Council } \\
\text { PPS = palliative performance scale } \\
\text { TLC = total lung capacity } \\
\text { FRC = functional residual capacity } \\
\text { RV = residual volume } \\
D_{\text {LCO }}=\text { diffusing capacity of the lung for carbon monoxide } \\
\mathrm{V}_{\mathrm{A}}=\text { alveolar volume measured by single breath gas dilution } \\
\mathrm{D}_{\mathrm{LCO}} / \mathrm{V}_{\mathrm{A}}=\mathrm{D}_{\mathrm{LCO}} \text { corrected for alveolar volume } \\
\text { SABA = short-acting } \beta_{2} \text {-agonist } \\
\text { SAMA = short-acting muscarinic antagonist } \\
\text { LABA = long-acting } \beta_{2} \text {-agonist } \\
\text { LAMA = long-acting muscarinic antagonist } \\
\text { ICS }=\text { inhaled corticosteroid }\end{array}$ & \\
\hline
\end{tabular}

characteristics of the subjects and inhaled medications are summarized in Table 2. Almost all the subjects were on triple inhaled therapy. Fourteen of the 45 subjects (31\%) were deceased at the time of the analysis.

Comorbid conditions were anxiety and/or depression (53\% of the subjects), systemic hypertension (38\%), and obstructive sleep apnea ( $31 \%$ [all were on CPAP]), extrapulmonary cancer $(20 \%)$, pulmonary hypertension (18\%), well-controlled heart failure (16\%), ischemic heart 


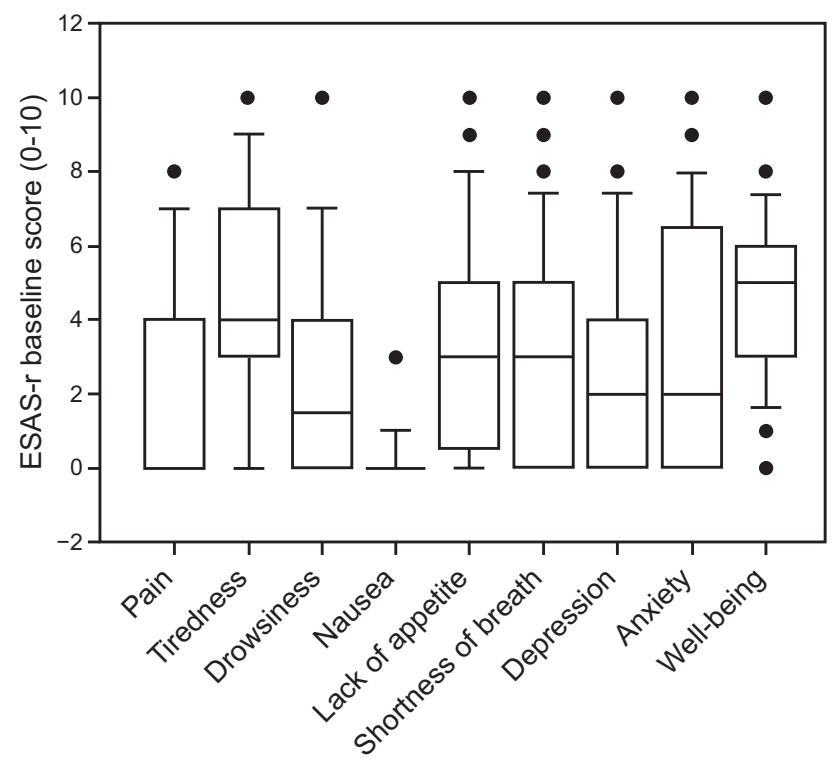

Fig. 2. Baseline revised Edmonton Symptom Assessment System (ESAS-r) score of the 9 domains in subjects with COPD. Boxes depict the first to third quartile (ie, the middle half of the data), whereas the center line shows the median. Whiskers range from the 10th to the 90th percentile.

Table 3. Interventions Through the Dyspnea Clinic

\begin{tabular}{lc}
\hline \hline \multicolumn{1}{c}{ Intervention } & Subjects, $n(\%)$ \\
\hline $\begin{array}{l}\text { Smoking cessation advice and/or support to } \\
\text { current smokers }(n=4)\end{array}$ & $4(100)$ \\
$\begin{array}{l}\text { Review of inhaled therapy technique } \\
\text { Sleep hygiene }\end{array}$ & $45(100)$ \\
Self-management plan & $14(31)$ \\
Pharmacologic & $45(100)$ \\
$\quad$ Opioids & \\
$\quad$ Methotrimeprazine & $40(89)$ \\
Nutritional advice & $14(31)$ \\
Referral to community palliative care & $11(24)$ \\
New oxygen therapy prescription & $24(53)$ \\
End-of-life discussion & $14(31)$ \\
\hline
\end{tabular}

disease (13\%), and well-controlled diabetes mellitus (11\%). At the time of the study, 22 subjects (49\%) had previously participated in a pulmonary rehabilitation program, and none participated in this program after the first clinic visit. Baseline ESAS-r scores for all domains are shown in Figure 2, and the baseline ESAS-r score for the shortness of breath domain was $3.07 \pm 2.86$ (mean $\pm \mathrm{SD}$ ).

Interventions first introduced through the clinic are summarized in Table 3. Eighty-nine percent of the subjects were prescribed systemic opioids to control their refractory breathlessness, and $31 \%$ were prescribed methotrimeprazine. Opioids were prescribed in the form of hydromorphone controlled-release $(3,6$, or $12 \mathrm{mg}$ every $12 \mathrm{~h}$ and/or hydromorphone $0.5-2 \mathrm{mg}$ every $4 \mathrm{~h}$ as a breakthrough intervention, and a few subjects $(n=6)$ were prescribed morphine instead, depending on the subject's status, comorbid condition, and response to initial dosage. The usual plan was to start with very-low-dose immediate-release hydromorphone $(0.5 \mathrm{mg}$ ) given every $4 \mathrm{~h}$ (or morphine $2.5 \mathrm{mg}$ every $4 \mathrm{~h}$ ) and slowly titrating the dose to effect while balancing and managing potential opioid-related adverse effects. Once an effective dose was found, the subjects were switched to sustained-release hydromorphone (or morphine) formulations. The hydromorphone controlled-release dose did not exceed $15 \mathrm{mg}$ every $12 \mathrm{~h}$, and the morphine-controlled release dose did not exceed $40 \mathrm{mg}$ every $12 \mathrm{~h}$ in any subject.

Immediate-release hydromorphone was provided in the subjects who were deemed reliable and to have a clear understanding of how to use a breakthrough dose. The subjects were educated to use a breakthrough dose $\sim 30$ $40 \mathrm{~min}$ before activities that regularly caused increased breathlessness (eg, showering, going out of the house, before exercise). The subjects were specifically instructed not to use breakthrough doses for increased dyspnea related to an acute COPD exacerbation. If a subject had a tendency to overuse inhalers or other medications or if the subject had a history of substance abuse, then he or she was not prescribed a breakthrough opioid dose.

Fourteen subjects $(31 \%)$ were prescribed long-term oxygen therapy for the first time through the clinic. Most subjects (82\%) were involved in discussions related to their goals of care and the illness trajectory for COPD, and $53 \%$ of the subjects were referred to home and community care programs for palliative care supports in the home.

\section{Primary and Secondary Outcomes}

The median time for follow up was 1.61 months (interquartile range, $1.38-2.07$ months). The primary and secondary outcomes in the whole sample $(N=45)$ are shown in Table 4. Responses to the intervention were variable and the mean change in ESAS-r score for shortness of breath in the total group was $-0.32 \pm 3.39(P=.53)$. There were no differences in all other ESAS-r domains at follow-up except for a higher score for drowsiness. In the whole group, there were no differences in hospital admissions or ED visits at follow-up, whether this was for any reason or for a respiratory condition (all $P>.05$ ) (Table 4).

\section{Responder Versus Nonresponder Subanalysis}

Of the 45 subjects, $47 \%(n=21)$ were identified as responders. The differences in ESAS-r scores for all domains at follow-up from baseline are shown in Figure 3. 
Table 4. Primary and Secondary Outcomes in the Whole Sample

\begin{tabular}{|c|c|c|}
\hline Variable & Baseline & Follow-up* \\
\hline \multicolumn{3}{|l|}{$\begin{array}{l}\text { Primary outcome: ESAS-r scores } \\
\quad(0-10), \text { mean } \pm \text { SD }\end{array}$} \\
\hline Pain & $1.98 \pm 2.65$ & $2.18 \pm 3.01$ \\
\hline Tiredness & $4.71 \pm 3.10$ & $4.69 \pm 2.76$ \\
\hline Drowsiness & $2.48 \pm 2.87$ & $3.44 \pm 2.89 \dagger$ \\
\hline Nausea & $0.20 \pm 0.66$ & $0.56 \pm 1.34$ \\
\hline Lack of appetite & $3.47 \pm 2.89$ & $3.36 \pm 2.54$ \\
\hline Shortness of breath & $3.07 \pm 2.86$ & $2.74 \pm 2.76$ \\
\hline Depression & $2.47 \pm 2.81$ & $2.31 \pm 3.02$ \\
\hline Anxiety & $3.42 \pm 3.25$ & $3.09 \pm 2.85$ \\
\hline Well-being & $4.44 \pm 2.31$ & $4.69 \pm 2.56$ \\
\hline \multicolumn{3}{|c|}{$\begin{array}{l}\text { Secondary outcome: annual hospital } \\
\text { admission and ED visits, } \\
\text { median (range) }\end{array}$} \\
\hline Admission due to any reason & $1(0-8)$ & $0(0-14)$ \\
\hline $\begin{array}{l}\text { Admission due to respiratory } \\
\text { condition }\end{array}$ & $0(0-5)$ & $0(0-13)$ \\
\hline ED visits due to any reason & $1(0-10)$ & $1(0-22)$ \\
\hline $\begin{array}{l}\text { ED visit due to respiratory } \\
\text { condition }\end{array}$ & $0(0-7)$ & $0(0-12)$ \\
\hline \multicolumn{3}{|c|}{$\begin{array}{l}N=45 \text {. } \\
* \text { Follow-up for ESAS-r was the follow-up visit between } 1 \text { and } 3 \text { months after the initial } \\
\text { (baseline) visit and was labelled as the 2-month visit for assessment of symptomatic } \\
\text { responses. For the secondary outcome, the comparisons were made for annual visits in the } \\
\text { year before and the second year after the first clinic visit. } \\
\dagger P<.05 \text { baseline vs follow-up. } \\
\text { ESAS-r = revised version of the Edmonton Symptom Assessment System } \\
\text { ED }=\text { emergency department }\end{array}$} \\
\hline
\end{tabular}

Apart from the shortness of breath domain, 42, 40, 40, and $33 \%$ of the 45 subjects met the minimum clinically important difference for improvement in ESAS-r score for domains of tiredness, anxiety, well-being, and depression, respectively. Comparisons between patients with COPD who were responders and nonresponders showed no significant differences in age, body mass index, baseline MRC dyspnea scale, or smoking history (Table 5). In addition, the 2 groups were similar in reported comorbidities and in the interventions applied through the clinic. The mean differences (between baseline and follow-up) for the ESAS-r score for domains other than shortness of breath were similar in the 2 groups except for well-being, which was better in responders $(P=.044)$ (Table 5). The subjects who were responders had a higher baseline ESAS-r score for shortness of breath domain compared with nonresponders $(4.86 \pm 2.63$ vs $1.50 \pm 2.04$, mean $\pm \mathrm{SD}$, $P<.001$ ), but $50 \%$ of nonresponders had baseline ESAS- $r$ scores for shortness of breath of $\geq 1$.

The subjects with COPD who were responders had fewer annual ED visits due to any reason in the second year after the first clinic visit compared with nonresponders $(1.38 \pm 1.63$ vs $4.45 \pm 5.52, P=.034)$. There was no difference between responders and nonresponders in the frequency of annual hospital admissions (Fig. 4). The subjects who were nonresponders had more annual ED visits in the 2 years after the first visit compared with 1 year before their first clinic visit $(4.45 \pm 5.52$ vs $2.04 \pm 3.22$; $P=.01)$.

\section{Discussion}

The main findings of the current study were (1) our results did not meet the primary outcome of the study: mean ESAS-r scores were not different before and after enrollment in the advanced dyspnea clinic in the whole sample; and (2) A post hoc analysis identified responders (21/45) and nonresponders based on whether they reached the minimum clinically important difference for the dyspnea domain of the ESAS-r; responders had less frequent annual ED visits after being followed up in this specialized clinic compared with nonresponders.

The current study included a well-characterized group of subjects with advanced COPD (average $\mathrm{FEV}_{1}$ of $36 \%$ predicted) who had severe exertional dyspnea as assessed by the MRC dyspnea scale. As previously reported, ${ }^{16}$ obstructive sleep apnea is a commonly reported comorbid condition in patients with COPD ( $31 \%$ of our sample), and all subjects with this diagnosis were using CPAP. In addition, 53\% of the subjects with COPD had anxiety and/or depression defined at their initial assessment visit. Our results were in keeping with previous studies in which anxiety, panic disorders, or depression was reported in 20 to $60 \%$ of subjects with COPD, depending on the disease stage and the scale used. ${ }^{17-20}$

The primary tenets of palliative care are to optimize symptom management and quality of life throughout the illness journey, plus establishment of goals of care that are in keeping with the patient's values and preferences. The role of palliative care comes into play when the usual disease-specific pharmacologic and nonpharmacologic treatment options are optimized. This specialized clinic was established with comprehensive care provided by a palliative care physician (IAH) and a nurse practitioner specialist $(\mathrm{EH})$ to help patients with advanced COPD who have chronic severe exertional dyspnea (MRC dyspnea score of $\geq 4$ of 5), despite optimized disease-specific therapies. We used the MRC dyspnea scale to identify those with severe exertional dyspnea who may benefit from attending this clinic. The MRC scale is the most widely used dyspnea scale, which measures the magnitude of the task required to cause breathlessness and has been previously linked to health outcomes. ${ }^{21}$ By contrast, the ESAS-r, a patient-rated symptom severity numeric scale, was used to evaluate patients' symptoms, including shortness of breath at initial and follow-up visits. ${ }^{22}$

At follow-up, subjects' responses, as assessed by using the ESAS-r, were variable and showed that, in the total sample, a change in the ESAS-r score for shortness of breath or an- 
Integrative Management of Severe Breathlessness in COPD

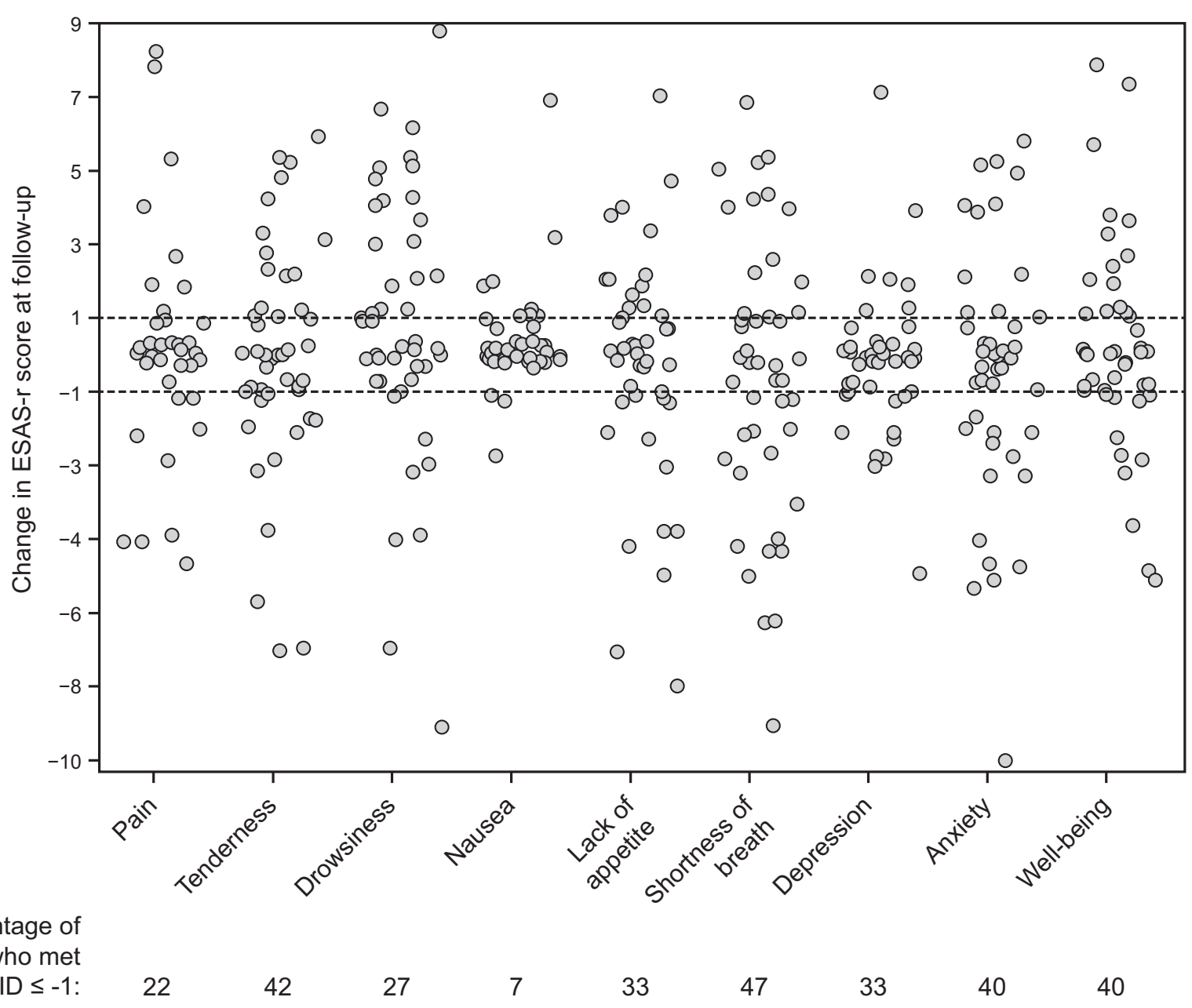

Fig. 3. Follow-up revised Edmonton Symptom Assessment System (ESAS-r) score in the 45 subjects with COPD. The values are individual data points of the differences between the baseline and the follow-up visit. The figure also shows the percentage of the subjects who met the minimum clinically important difference (MCID) of improvement of least -1 for each domain. Dotted lines denote minimum clinically important difference.

nual ED and/or hospital visits did not reach statistical significance. However, in a secondary analysis, $47 \%$ of the subjects were identified as responders (ie, met the minimum clinically important difference for improvement in the ESAS-r shortness of breath domain at follow-up) and $40 \%$ showed improvements in ESAS-r scores for anxiety and general wellbeing. In the subset of the subjects who reached the ESAS-r minimum clinically important difference for dyspnea domain, there was an additional reduction of the frequency of annual ED visits. As such, the responders had significantly less frequent (by $31 \%$ ) ED visits compared with the nonresponders in the second year after their first visit to this clinic. Responders and nonresponders had similar baseline MRC dyspnea scores, clinical characteristics, baseline lung function, and comorbid conditions.

This specialized clinic was established to provide holistic care (total person care) that draws on integrated palliative care for patients who are severely breathless and with chronic respiratory diseases. As per the results of a recent systematic review that included 37 articles that discussed holistic services for patients with advanced disease and chronic breathlessness, such services are usually offered to patients with thoracic cancer and are mostly short term (4-6 weeks). ${ }^{23}$ Our intention was to provide support to patients with distressing breathlessness, especially in noncancer conditions, in which such service is not usually available. In our clinic, the patients were followed up for as long as they were in need or until they were no longer able to come to the clinic, and they were were referred for ongoing follow up at home by their family physician or a community palliative care physician. Clinic visits lasted 30 to 60 min per patient. Family members and friends were encouraged to attend these clinics where there was ample opportunity for detailed discussions and planning. The clinic provided multiple services, including smoking cessation support, educational advice about the disease 
Table 5. Comparison Between Patients With COPD: Responders and Nonresponders

\begin{tabular}{|c|c|c|c|}
\hline Variable & $\begin{array}{l}\text { Responders } \\
(n=21)\end{array}$ & $\begin{array}{l}\text { Nonresponders } \\
\quad(n=24)\end{array}$ & $P$ \\
\hline \multicolumn{4}{|l|}{ Demographics } \\
\hline $\mathrm{M}: \mathrm{F}, n$ & 10:11 & $15: 9$ & NA \\
\hline Age, mean \pm SD y & $69 \pm 7$ & $72 \pm 7$ & .17 \\
\hline $\mathrm{BMI}$, mean $\pm \mathrm{SD} \mathrm{kg} / \mathrm{m}^{2}$ & $28 \pm 15$ & $29 \pm 19$ & .96 \\
\hline $\begin{array}{l}\text { MRC dyspnea score }(1-5) \\
\text { mean } \pm \text { SD }\end{array}$ & $4.78 \pm 0.43$ & $4.71 \pm 0.46$ & .66 \\
\hline $\begin{array}{l}\text { Baseline ESAS-r score for } \\
\text { shortness of breath, } \\
\text { mean } \pm \text { SD }\end{array}$ & $4.86 \pm 2.63$ & $1.50 \pm 2.04$ & $<.001$ \\
\hline \multicolumn{4}{|l|}{$\begin{array}{l}\text { Pulmonary function test } \\
\text { mean } \pm \text { SD }\end{array}$} \\
\hline $\mathrm{FEV}_{1}, \%$ predicted & $37 \pm 21$ & $34 \pm 16$ & .54 \\
\hline FVC, $\%$ predicted & $69 \pm 16$ & $64 \pm 18$ & .34 \\
\hline $\mathrm{FEV}_{1} / \mathrm{FVC}, \%$ & $36 \pm 14$ & $37 \pm 10$ & .66 \\
\hline $\begin{array}{l}\text { Inspiratory capacity, } \% \\
\text { predicted }\end{array}$ & $76 \pm 21$ & $72 \pm 27$ & .63 \\
\hline FRC, $\%$ predicted & $183 \pm 45$ & $175 \pm 53$ & .59 \\
\hline TLC, $\%$ predicted & $134 \pm 41$ & $135 \pm 29$ & .93 \\
\hline $\mathrm{RV}, \%$ predicted & $231 \pm 76$ & $219 \pm 78$ & .65 \\
\hline $\mathrm{RV} / \mathrm{TLC}, \%$ & $61 \pm 13$ & $63 \pm 11$ & .58 \\
\hline $\mathrm{D}_{\mathrm{LCO}}, \%$ predicted & $51 \pm 31$ & $49 \pm 16$ & .75 \\
\hline \multicolumn{4}{|l|}{ Comorbidities, $n(\%)$} \\
\hline Diabetes mellitus & $0(0)$ & $5(21)$ & .051 \\
\hline Systemic hypertension & $8(38)$ & $9(38)$ & $>.99$ \\
\hline Ischemic heart disease & $3(14)$ & $3(13)$ & $>.99$ \\
\hline Heart failure & $2(10)$ & $5(21)$ & .42 \\
\hline Extrapulmonary cancer & $4(19)$ & $5(21)$ & $>.99$ \\
\hline Obstructive sleep apnea & $5(24)$ & $9(38)$ & .34 \\
\hline Pulmonary hypertension & $3(14)$ & $5(21)$ & .71 \\
\hline Anxiety and/or depression & $10(48)$ & $14(58)$ & .56 \\
\hline \multicolumn{4}{|l|}{$\begin{array}{l}\text { Difference of the ESAS-r score } \\
\text { between baseline and } \\
\text { follow-up, mean } \pm \text { SD }\end{array}$} \\
\hline Pain & $0.00 \pm 2.32$ & $0.38 \pm 2.73$ & .63 \\
\hline Tiredness & $-0.62 \pm 2.77$ & $0.50 \pm 2.93$ & .20 \\
\hline Drowsiness & $0.71 \pm 3.84$ & $1.00 \pm 3.13$ & .79 \\
\hline Nausea & $0.14 \pm 0.96$ & $0.54 \pm 1.59$ & .32 \\
\hline Lack of appetite & $-0.14 \pm 2.41$ & $-0.08 \pm 3.19$ & .95 \\
\hline Shortness of breath & $-3.17 \pm 2.11$ & $2.17 \pm 2.08$ & $<.001$ \\
\hline Depression & $0.19 \pm 1.97$ & $-0.46 \pm 1.74$ & .25 \\
\hline Anxiety & $-0.24 \pm 2.64$ & $-0.42 \pm 3.57$ & .85 \\
\hline Well-being & $-0.62 \pm 2.13$ & $1.00 \pm 2.96$ & .044 \\
\hline $\begin{array}{l}\text { NA }=\text { not applicable } \\
\text { BMI }=\text { body mass index } \\
\text { MRC = Medical Research Council } \\
\text { ESAS-r }=\text { revised version of the Edmont } \\
\text { FRC }=\text { functional residual capacity } \\
\text { TLC }=\text { total lung capacity } \\
\text { RV = residual volume }\end{array}$ & on Symptom Assessn & nent System & \\
\hline
\end{tabular}

and its treatments, a review of inhaled therapy techniques, collaborative self-management plans, and sleep hygiene advice, all on an individualized basis.
Furthermore, based on the subjects' requirements, targeted pharmacologic interventions that mainly included opioids, methotrimeprazine, and oxygen therapy were also offered. Opiate therapy is the most studied class of pharmacologic agents for relieving refractory dyspnea across different disease states. ${ }^{24,25}$ Some studies demonstrated that the judicious use of oral opioids modestly but significantly improved dyspnea ratings, with only trivial insignificant worsening of pulmonary gas exchange (carbon dioxide level, arterial oxygen saturation), ${ }^{26-29}$ even in a frail older population. ${ }^{30,31}$ In our sample, most of those referred $(89 \%)$ were prescribed oral opioids with the dose slowly up-titrated to decrease the severity of severe dyspnea experienced and with regular follow-up of their arterial blood gases. In addition, $31 \%$ of our subjects were prescribed methotrimeprazine to help with dominant respiratory-related anxiety and panic attacks. Given that the intervention (pharmacologic and nonpharmacologic) applied through this clinic was not offered in a stepwise manner (one intervention at a time), we could not assess the impact on breathlessness of each component in isolation.

A recent systematic review highlighted that only a small percentage of subjects with COPD had discussed the role of palliative care with their clinicians. ${ }^{32}$ Clinicians in busy pulmonology clinics do not facilitate satisfactory conversations that identify patients' preferences in the advanced phases of disease. Indeed, in the current study, end-of-life issues had not been previously discussed in the majority of referred patients before their enrollment in the advanced dyspnea clinic. Within this clinic, $82 \%$ of the subjects became engaged in end-of-life care discussions and goals of care preferences. Our results showed that this clinic not only provided new pharmacologic treatments for this patient population but provided other support, such as advance care planning, nutritional advice, referral to spiritual care or social work, and referral to community homebased palliative care services to promote continuity of care in the patient's choice of location. Collectively, these results demonstrated that such specialized clinics help mobilize additional resources and provide more comprehensive management in patients with severe refractory dyspnea than what can be offered in busy general pulmonology clinics.

Dyspnea is an intensely personal experience not easily captured numerically on various scales currently at our disposal. The expression of dyspnea is highly variable across individuals, with wide variation in precipitating events (eg, diurnal pattern, anxiety, physical activity, body position, sputum impaction, coughing spell). The affective dimensions of the symptom are also variable across individuals and must be considered if effective treatment is to be offered. Many of our subjects with refractory dyspnea had full-blown panic attacks 

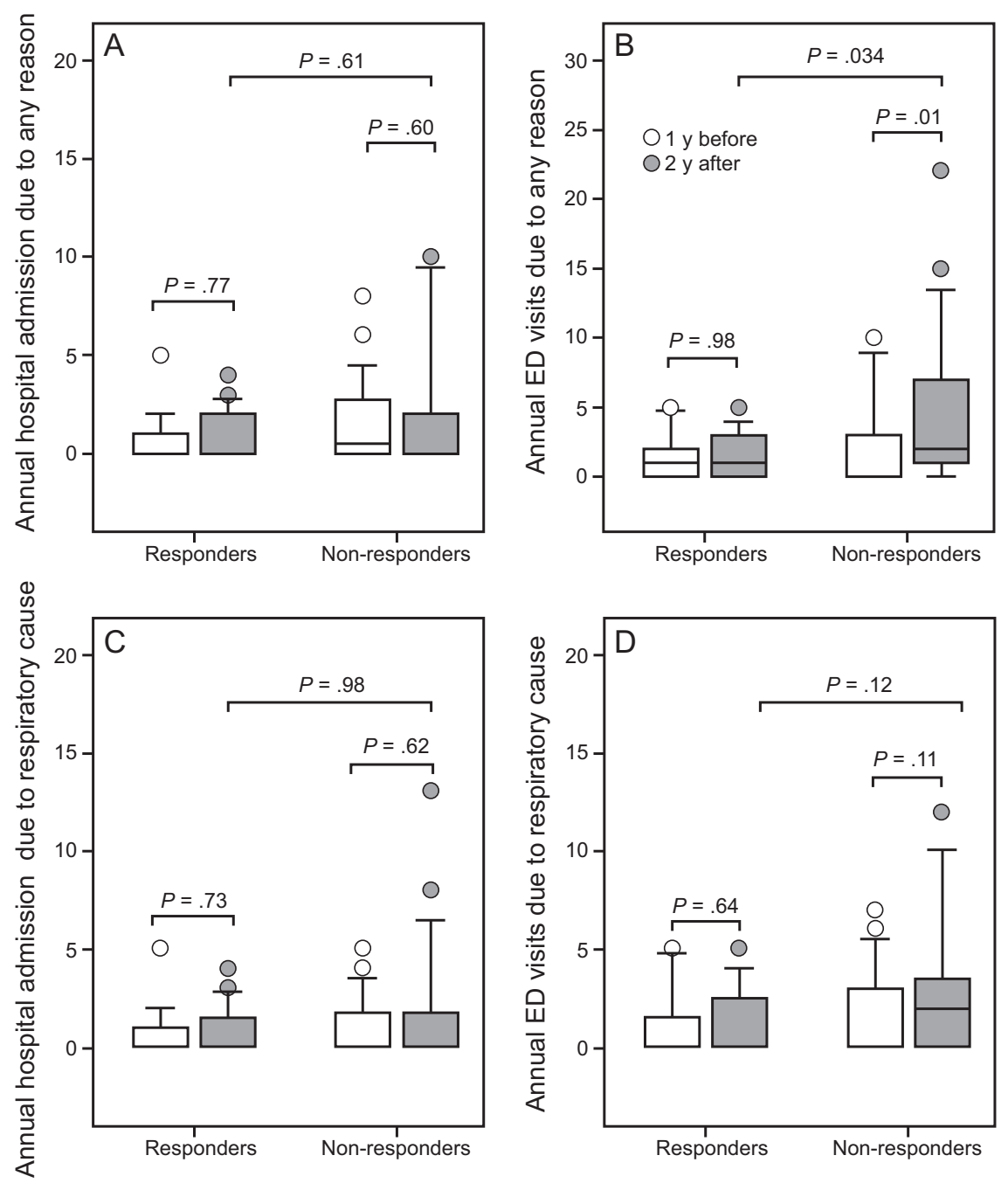

Fig. 4. Annual hospital admission and emergency department (ED) visits 1 year before and 2 years after the first clinic visit in subjects with COPD (responders and nonresponders) whether due to any reason ( $A$ and $B$ ) or due to respiratory cause $(C$ and $D)$. Responders are defined as those with at least a -1 change in ESAS-r score for the shortness of breath domain at follow-up. Boxes depict the first to third quartiles; center lines denote the median. Whiskers range from the 10th to the 90th percentile. The Wilcoxon rank-sum test was used for betweengroups comparisons in the 2 years after the first clinic visit and Wilcoxon signed-rank test was used for pre-post comparisons with each group. ESAS-r = revised Edmonton Symptom Assessment System.

related to breathing discomfort, and, in some, these could escalate to "dyspnea crisis," which precipitated emergency admissions to the hospital. In the clinic, comprehensive questioning and exploration of each individual's dyspnea experience was undertaken, and, accordingly, personalized targeted management strategies were initiated (Fig. 1). Anecdotally, this approach was successful in most subjects who reported consistent subjective benefit. Unfortunately, important personal qualitative benefits were underestimated when using the minimum clinically important difference from the dyspnea component of the ESAS-r scale. More-refined assessments of symptom improvement that focus on the response of individuals to structured interventions are clearly needed.

\section{Limitations}

This was a retrospective study and lacked a control arm to more definitively determine the causal impact of a specialized clinic and its individual components in caring for patients with refractory dyspnea. Furthermore, the small sample size and single-center design may limit the generalizability of results. The small sample size might also be responsible for the lack of possible differences in baseline clinical characteristics of the responder and nonresponder groups. Nevertheless, this preliminary analysis provided important information that will allow refinements in study design for future studies in this neglected population. The interval between follow-up visits was not consistent; this 


\section{Integrative Management of Severe Breathlessness in COPD}

affected our analysis of responders versus nonresponders and allowed us to only look at the short-term response for this study in a subset of subjects. The ESAS-r is a validated instrument mainly used to assess the change in severity of symptoms over time and the response to therapeutic interventions in patients with cancer. The wide disparity between assessments of dyspnea by using the MRC scale, which indicated disabling dyspnea (an inclusion criterion), and the ESAS-r shortness of breath score, which, in some individuals indicated only minor shortness of breath, indicated that the latter may not be the best tool to assess symptoms and response to treatment in patients with chronic respiratory disease.

\section{Conclusions}

Our study provides insights into the role of a specialized advanced dyspnea clinic in improving dyspnea and other patient-centered outcomes in subjects with advanced COPD, who, unfortunately, are destined to progressively deteriorate over time. The study showed that a specialized clinic provided short-term, clinically meaningful improvements in dyspnea and other subjective outcomes, with significant reduction in hospital emergency visits in a good proportion of the sample. Our preliminary study set the stage for new randomized controlled studies to evaluate the efficacy and, it is hoped, provide further justification for specialized clinics for the palliative care management of refractory dyspnea in persons with advanced respiratory diseases.

\section{REFERENCES}

1. Buist AS, McBurnie MA, Vollmer WM, Gillespie S, Burney P, Mannino DM, et al; BOLD Collaborative Research Group. International variation in the prevalence of COPD (the BOLD study): a population-based prevalence study. Lancet 2007;370(9589):741750.

2. Parshall MB, Schwartzstein RM, Adams L, Banzett RB, Manning HL, Bourbeau J, et al; American Thoracic Society Committee on Dyspnea. An official American Thoracic Society statement: update on the mechanisms, assessment, and management of dyspnea. Am J Respir Crit Care Med 2012;185(4):435-452.

3. Elkington H, White P, Addington-Hall J, Higgs R, Edmonds P. The healthcare needs of chronic obstructive pulmonary disease patients in the last year of life. Palliat Med 2005;19(6):485-491.

4. Nishimura $K$, Izumi $T$, Tsukino $M$, Oga $T$. Dyspnea is a better predictor of 5-year survival than airway obstruction in patients with COPD. Chest 2002;121(5):1434-1440.

5. Solano JP, Gomes B, Higginson IJ. A comparison of symptom prevalence in far advanced cancer, AIDS, heart disease, chronic obstructive pulmonary disease and renal disease. J Pain Symptom Manage 2006;31(1):58-69.

6. O'Donnell DE, Webb KA, Harle I, Neder JA. Pharmacological management of breathlessness in COPD: recent advances and hopes for the future. Expert Rev Respir Med 2016;10(7):823-834.
7. Luckett T, Phillips J, Johnson MJ, Farquhar M, Swan F, Assen T, et al. Contributions of a hand-held fan to self-management of chronic breathlessness. Eur Respir J 2017;50(2). pii: 1700262.

8. Booth S, Moffat C, Burkin J, Galbraith S, Bausewein C. Nonpharmacological interventions for breathlessness. Curr Opin Support Palliat Care 2011;5(2):77-86.

9. Woodcock AA, Gross ER, Geddes DM. Drug treatment of breathlessness: contrasting effects of diazepam and promethazine in pink puffers. Br Med J (Clin Res Ed) 1981;283(6287):343-346.

10. Mahler DA, Weinberg DH, Wells CK, Feinstein AR. The measurement of dyspnea. Contents, interobserver agreement, and physiologic correlates of two new clinical indexes. Chest 1984;85(6):751-758.

11. Bruera E, Kuehn N, Miller MJ, Selmser P, Macmillan K. The Edmonton Symptom Assessment System (ESAS): a simple method for the assessment of palliative care patients. J Palliat Care 1991;7(2): 6-9.

12. Anderson F, Downing GM, Hill J, Casorso L, Lerch N. Palliative performance scale (PPS): a new tool. J Palliat Care 1996;12(1):5-11.

13. Hui D, Bruera E. The Edmonton Symptom Assessment System 25 years later: past, present, and future developments. J Pain Symptom Manage 2017;53(3):630-643.

14. Watanabe SM, Nekolaichuk C, Beaumont C, Johnson L, Myers J, Strasser F. A multicenter study comparing two numerical versions of the Edmonton Symptom Assessment System in palliative care patients. J Pain Symptom Manage 2011;41(2):456-468.

15. Hui D, Shamieh O, Paiva CE, Khamash O, Perez-Cruz PE, Kwon $\mathrm{JH}$, et al. Minimal clinically important difference in the physical, emotional, and total symptom distress scores of the Edmonton Symptom Assessment System. J Pain Symptom Manage 2016;51(2):262269.

16. Krachman S, Minai OA, Scharf SM. Sleep abnormalities and treatment in emphysema. Proc Am Thorac Soc 2008;5(4):536-542.

17. Spitzer C, Gläser S, Grabe HJ, Ewert R, Barnow S, Felix SB, et al. Mental health problems, obstructive lung disease and lung function: findings from the general population. J Psychosom Res 2011;71(3): 174-179.

18. Schneider C, Jick SS, Bothner U, Meier CR. COPD and the risk of depression. Chest 2010;137(2):341-347.

19. Kunik ME, Roundy K, Veazey C, Souchek J, Richardson P, Wray NP, Stanley MA. Surprisingly high prevalence of anxiety and depression in chronic breathing disorders. Chest 2005;127(4):12051211.

20. van Manen JG, Bindels PJ, Dekker FW, Ijzermans CJ, van der Zee JS, Schadé E. Risk of depression in patients with chronic obstructive pulmonary disease and its determinants. Thorax 2002;57(5):412-416.

21. Jones PW, Adamek L, Nadeau G, Banik N. Comparisons of health status scores with MRC grades in COPD: implications for the GOLD 2011 classification. Eur Respir J 2013;42(3):647-654.

22. Chang VT, Hwang SS, Feuerman M. Validation of the Edmonton Symptom Assessment Scale. Cancer 2000;88(9):2164-2171.

23. Brighton LJ, Miller S, Farquhar M, Booth S, Yi D, Gao W, et al. Holistic services for people with advanced disease and chronic breathlessness: a systematic review and meta-analysis. Thorax 2019;74(3): 270-281.

24. Mahler DA, Murray JA, Waterman LA, Ward J, Kraemer WJ, Zhang X, Baird JC. Endogenous opioids modify dyspnoea during treadmill exercise in patients with COPD. Eur Respir J 2009;33(4):771-777.

25. Jennings AL, Davies AN, Higgins JP, Gibbs JS, Broadley KE. A systematic review of the use of opioids in the management of dyspnoea. Thorax 2002;57(11):939-944.

26. Clemens KE, Quednau I, Klaschik E. Is there a higher risk of respiratory depression in opioid-naive palliative care patients during symptomatic therapy of dyspnea with strong opioids? J Palliat Med 2008; 11(2):204-216. 


\section{Integrative Management of Severe Breathlessness in COPD}

27. Clemens KE, Klaschik E. Symptomatic therapy of dyspnea with strong opioids and its effect on ventilation in palliative care patients. J Pain Symptom Manage 2007;33(4):473-481.

28. Vozoris NT, Wang X, Fischer HD, Gershon AS, Bell CM, Gill SS, et al. Incident opioid drug use among older adults with chronic obstructive pulmonary disease: a population-based cohort study. Br J Clin Pharmacol 2016;81(1):161-170.

29. Vozoris NT, O’Donnell DE, Gill SS. Opioids and adverse outcomes in elderly chronic obstructive pulmonary disease patients. Eur Respir J 2016;48(6):1818.
30. Currow DC, McDonald C, Oaten S, Kenny B, Allcroft P, Frith P, et al. Once-daily opioids for chronic dyspnea: a dose increment and pharmacovigilance study. J Pain Symptom Manage 2011;42(3):388399.

31. Currow DC, Ekström M, Johnson MJ. The strength of evidence: low dose morphine for chronic breathlessness. Intern Med J 2018;48(1): 102-103.

32. Tavares N, Jarrett N, Hunt K, Wilkinson T. Palliative and end-of-life care conversations in COPD: a systematic literature review. ERJ Open Res 2017;3(2). pii: 00068-2016. 